\title{
Exploring the contemporary ethical challenges in coaching psychology in South Africa
}

\begin{tabular}{|c|c|}
\hline \multicolumn{2}{|c|}{$\begin{array}{l}\text { Authors: } \\
\text { Claire E. Simon }^{1} \\
\text { Aletta Odendaal }^{1} \\
\text { Xenia Goosen }^{1}\end{array}$} \\
\hline \multicolumn{2}{|c|}{$\begin{array}{l}{ }^{1} \text { Department of Industrial } \\
\text { Psychology and People } \\
\text { Management, University of } \\
\text { Johannesburg, South Africa }\end{array}$} \\
\hline \multicolumn{2}{|c|}{$\begin{array}{l}\text { Correspondence to: } \\
\text { Claire Simon }\end{array}$} \\
\hline \multicolumn{2}{|c|}{$\begin{array}{l}\text { Email: } \\
\text { claireys7@gmail.com }\end{array}$} \\
\hline \multicolumn{2}{|c|}{$\begin{array}{l}\text { Postal address: } \\
\text { Postnet Suite 101, Private } \\
\text { Bag X12, Roosevelt Park } \\
2129 \text {, South Africa }\end{array}$} \\
\hline \multicolumn{2}{|c|}{$\begin{array}{l}\text { Dates: } \\
\text { Received: } 17 \text { Dec. } 2013 \\
\text { Accepted: } 18 \text { June } 2014 \\
\text { Published: } 25 \text { Nov. } 2014 \\
\text { Republished: } 05 \text { Dec. } 2014\end{array}$} \\
\hline \multicolumn{2}{|c|}{$\begin{array}{l}\text { How to cite this article: } \\
\text { Simon, C.E., Odendaal, A., \& } \\
\text { Goosen, X. (2014). Exploring } \\
\text { the contemporary ethical } \\
\text { challenges in coaching } \\
\text { psychology in South Africa. } \\
\text { SA Journal of Industrial } \\
\text { Psychology/SA Tydskrif vir } \\
\text { Bedryfsielkunde, 40(1), Art. } \\
\text { \#1191, } 15 \text { pages. } \\
\text { http://dx.doi.org/10.4102/ } \\
\text { sajip.v40i1.1191 }\end{array}$} \\
\hline \multicolumn{2}{|c|}{$\begin{array}{l}\text { Note: } \\
\text { This article has been } \\
\text { republished with the removal } \\
\text { of the duplicate Figure } 1 .\end{array}$} \\
\hline \multicolumn{2}{|c|}{$\begin{array}{l}\text { Copyright: } \\
\text { (C) 2014. The Authors } \\
\text { Licensee: AOSIS } \\
\text { OpenJournals. This w } \\
\text { is licensed under the } \\
\text { Creative Commons } \\
\text { Attribution License. }\end{array}$} \\
\hline Read online: & $\begin{array}{l}\text { Scan this QR } \\
\text { code with your } \\
\text { smart phone or } \\
\text { mobile device } \\
\text { to read online. }\end{array}$ \\
\hline
\end{tabular}

Orientation: This article focuses on the contemporary ethical challenges in coaching psychology in the South African context.

Research purpose: The primary objective was to qualitatively explore the contemporary ethical challenges faced by coaching psychologists when coaching clients and organisations and develop an exploratory framework of ethical challenges.

Motivation for the study: There may not be sufficient practical guidance to resolving the ethical challenges coaching psychologists encounter when coaching clients within organisations. In addition, available codes of ethics may not fundamentally cover all important ethical challenges, particularly in the South African context.

Research approach, design and method: An interpretative paradigm with an explorative approach was applied. Semi-structured interviews and the Delphi technique were used to gather data from 16 participants who were purposively selected: six coaching psychologists were interviewed, whilst feedback from 10 expert panel members was obtained using the Delphi technique. The data was analysed using thematic analysis.

Main findings: The findings point to a number of common ethical challenges in coaching psychology, as well as the typical ethical principles used by psychologists who coach as a guide to best ethical practice. The exploratory framework represents the broad systemic outline of factors that contribute to the ethical challenges and articulates these from the coach's, coachee's and organisation's perspective.

Practical/managerial implications: The framework can be applied by professionals and coaching clients and can be utilised proactively in identifying potential ethical challenges in the coaching relationship.

Contribution/value-add: The framework identifies ethical principles that could be used as the foundation for a code of ethics in coaching psychology.

\section{Introduction}

Over the past 10 years, coaching has attracted considerable media coverage, both as a potential career and as a means of personal and professional development, and has drawn the attention of individuals as well as organisations (Grant, Passmore, Cavanagh \& Parker, 2010). In a study of 2529 professional coaches, Grant and Zackon (2004) report that the coaches came from a variety of prior careers, such as consultants $(40.8 \%)$, managers $(30.8 \%)$, executives $(30.2 \%)$, teachers $(15.7 \%)$, sales persons $(13.8 \%)$ and psychologists $(4.8 \%)$. It is therefore evident that a wide range of methodological approaches and educational disciplines could potentially inform the practice of coaching, which means that there may be a wide range of perspectives regarding what constitutes best ethical practice (Palmer \& Whybrow, 2007). Grant and Zackon (2004) further report that the majority of practising coaches are not psychologists or behavioural scientists and, when judged against the commonly accepted criteria for professional status, Grant et al. (2010) conclude that the coaching industry displays few of the standards applicable to these fields. There are no barriers to entering coaching (Spence \& Grant, 2007), no required training or qualifications and no enforceable ethical or practice standards (Bennett, 2006; Sherman \& Frees, 2004).

Coaching psychology ${ }^{1}$ as a recently emerging and applied sub-discipline of psychology, draws upon recognised psychological approaches and methods and also develops new ones (Green, Oades \& Grant, 2006). Odendaal and Le Roux (2011) describe coaching psychology as the conversational process of creating enhanced functioning, optimising potential and effecting change in work and life domains. This process is action-orientated and measureable

1.Regulations defining the scope of the profession of psychology in South Africa (No. 34581, 02 September 2011) do not make provision for registered psychologists who coach to register as coaching psychologists. In this article, the term coaching psychologist refers to a registered psychologist, in any of the recognised categories, who is also practising coaching. 
and uses established and positive psychological principles and theory at an individual, group, organisational and community level, within a multicultural context. As such, coaching psychology is of a non-clinical nature, whilst counselling entails the same process, but from a clinical perspective. In this regard, a definite line can be drawn between coaching psychology and counselling. Peltier (2010) indicates that the distinction between counselling and coaching relies on a focus on the primary value orientation of the two fields. Coaching typically takes place in the business context and the coach works with well-functioning clients; this differs from counselling or therapy, which places an emphasis on the 'ethic of care', and in which the client may be distressed or dysfunctional.

In this regard, Brennan and Wildflower (2010) indicate that coaching is run as a business and has to succeed in a competitive market place (Bennett, 2006); however, in conflict with the economic pressure to compete, there is the professional motivation to cooperate. Possible ethical challenges encountered by a psychologist when faced with this transition include: establishing who the client is, confidentiality, consent, boundaries, termination of the coaching relationship, as well as the duty to protect or warn. As such, coaching psychology deals fundamentally with the well-being and enhancement of individuals and organisations and is grounded in psychological principles. It is therefore important to explore the collaborative relationship between the coach and the coachee. Within this collaborative relationship, the identification of ethical challenges, as well as the supporting ethical principles, especially within a South African context, requires further exploration.

Ethical principles are the foundation of professional standards of practice (Grant, 2011) and may assist coaching psychologists in their work (Twain, 1995). However, within the field of coaching psychology, these principles of ethical conduct 'may fail to offer practical guidance for coaching psychologists in resolving the everyday ethical dilemmas which practitioners face when working with individuals and clients' (Duffy \& Passmore, 2010, p. 141). Professional coaching bodies each have their own code of ethics, which may not necessarily cover all the significant ethical challenges. These codes are sometimes considered overly prescriptive and valid only in a limited number of situations and are, furthermore, considered to contain principles that are contradictory when applied to specific ethical challenges (Duffy \& Passmore, 2010). In addition, Grant (2011) indicates that the codes of ethics appropriate for a psychologist who coaches may well differ from the codes that are made available to a non-psychologist who coaches.

Whilst the importance of ethics in coaching has been discussed widely in coaching literature, it becomes increasingly evident that, within the practice of coaching psychology, there may not be sufficient practical guidance to resolving the ethical challenges encountered by coaching psychologists when both dealing with organisations and coaching clients within those organisations (Duffy \& Passmore, 2010). In addition, the available codes of ethics may not fundamentally cover all the important ethical challenges, particularly within the South African context.

As coaching psychology is multidisciplinary in nature, there may be a wide range of perspectives about what constitutes best ethical practice. Rossouw and Van Vuuren (2010) define ethics around three central concepts: the self, good and other. As such, ethical behaviour results when one does not merely consider what is good for oneself, but also what is good for others. Therefore, ethics seeks to serve one's own interests whilst simultaneously caring about the interests of others, which ultimately results in behaviour that is self-interested whilst remaining ethical (Rossouw \& Van Vuuren, 2010). Specific to this research study, the self and other may refer either to the coach, the coachee or the organisation, depending on the specific stakeholder viewpoint from which ethics is approached.

The coaching psychology process places emphasis on the dyadic relationships that exist between a coach and the other stakeholders in the coaching relationship (Duffy \& Passmore, 2010; Gregory \& Levy, 2012). Dual relationships (Brennan \& Wildflower, 2010) and multiple relationships (Duffy \& Passmore, 2010) include the coach and the coachee, director, senior manager, supervisor and/or the organisation as a whole. Brennan and Wildflower (2010), Duffy and Passmore (2010), Law (2005) and Stout-Rostron (2009) are of the opinion that the common ethical challenges that the coach may be faced with as a result of these dyadic and multiple relationships include the need to establish (1) who the clients are, (2) which stakeholders have priority, (3) whose interests the coach should be serving, (4) ethical duties, (5) how a variety of values and interests may be managed, (6) issues of confidentiality, (7) potential for the abuse of power and (8) the implications of indirect accountability.

Cavanagh and Lane (2012) indicate that coaching psychologists are continually faced with a variety of complex relationships that further intensify the ethical challenges that they may encounter when working in collaboration with coaching clients and organisations. When considering the variety of relationships between the coach and stakeholders in an organisation, ethical decision-making within the field of coaching psychology can be described as complicated (Duffy \& Passmore, 2010).

\section{Areas of concern impacting ethical decision-making}

A critical analysis of the relevant literature identified several areas of concern that may impact ethical decision-making and thus the need to explore the contemporary ethical challenges faced by coaching psychologists in South Africa.

The first area includes the key categories of coaching, emphasising the context, the content, the core consequences of the coaching engagement and the client (Cavanagh \& Grant, 2006). These four categories classify the source of 
ethical challenges that arise in the coaching process. Since the context differs across situations, the content may be dependent on the coach's scope of practice (Law, 2005; Stern \& Stout-Rostron, 2013); the coach is responsible for any consequences as a result of the coaching. Also, there are multiple clients involved in the coaching relationship (StoutRostron, 2009). When considering all these factors, it becomes evident that the psychologist as coach may be faced with a variety of ethical challenges, which were further explored in this study. The second area refers to the broad nature and multiple perspectives evident within the field of coaching (Duffy \& Passmore, 2010; Palmer \& Whybrow, 2007), which means that there may be a wide range of perspectives regarding what constitutes best ethical practice. The need for role awareness in the different categories of coaching (Brennan \& Wildflower, 2010; Duffy \& Passmore, 2010; Law, 2005; Lane \& Corrie, 2009; Palmer \& Whybrow, 2005), which each has a direct impact on the ethical challenges, is thus fundamental to the coaching relationship.

The third area of concern relates to the core themes relating to the purpose (Brennan \& Wildflower, 2010; Lane \& Corrie, 2009; Stout-Rostron, 2009), perspective (Lane \& Corrie, 2009; Palmer \& Whybrow, 2005; Stern \& Stout-Rostron, 2013) and process (Lane \& Corrie, 2009) of the coaching intervention. These three themes are aimed at providing a format that will enable coaching psychologists, whatever their theoretical orientation may be, to use the concept of case formulation to assist client change. According to Lane and Corrie (2009), the purpose seeks to establish the fundamental purpose of the encounter and the reason for working with a particular client, whilst the perspective entails gaining an understanding of those factors that influence the expectations of and inform the coaching process for both the coach and coachee. Once the purpose and the perspective have been successfully established, it is possible to structure the coaching process and the subsequent contracting (Duffy \& Passmore, 2010; Hazen \& Steckler, 2010; Spinelli, 2008; Stout-Rostron, 2009) that will be entered into by the coach and coachee.

The fourth area encompasses coaching psychology as a recently emerging and applied sub-discipline of psychology that draws upon recognised psychological approaches and methods and also develops new ones (Green et al., 2006). Whilst coaching is currently unlikely to achieve the status of a profession (Grant et al., 2010), it is moving towards the professional standards and practices of psychology (Gray, 2011), thereby creating a strong link between coaching and psychology. Grant (2006; 2010), Lane, Stelter and StoutRostron (2010) and Palmer and Whybrow (2005) make a strong case for both the suitability of psychologists to coach, as well as their credibility as professional coaches. As such, psychologists who coach in South Africa currently make use of the ethical guidelines provided by the Health Professions Council of South Africa's (HPCSA, 2004) Code of Ethics to ensure good ethical practice. Other standards of ethical conduct utilised by coaching psychologists include those provided by the International Coach Federation (ICF, 2011), the European Mentoring and Coaching Council, International Society for Coaching Psychology (ISCP, 2011), Coaches and Mentors of South Africa (COMENSA, 2006), as well as the Society for Industrial and Organisational Psychology of South Africa.

The aspiration to act ethically cannot be separated from the individual coach's understanding of what could possibly influence ethical decision-making. Through the review of the literature, it became evident that there may be a complexity of ethical challenges embedded in the multiple relationships within a coaching process, which means that there may be a wide range of perspectives about what constitutes best ethical practice. It was further expected that there may be some interaction between the different areas of ethical concern. The ethical codes currently utilised by psychologists who coach, though they attempt to define a set of behaviours, are limited in that they may not offer practical guidelines in resolving everyday ethical dilemmas that are faced by coaching psychologists, especially those specific to the South African context. To address these issues, the current study explored the following research question: What are the contemporary ethical challenges facing coaching psychologists in South Africa? As a result, the purpose of this study was to explore the contemporary ethical challenges that coaching psychologists in South Africa experience when working with coaching clients and organisations and, from this, develop an exploratory framework of ethical challenges.

\section{Research design Research approach}

A qualitative research approach was employed with the intent of gaining in-depth information and a deeper understanding of the ethical challenges that coaching psychologists face in South Africa. Guided by the researchers' ontology and epistemology, an interpretive paradigm and an exploratory approach were adopted in order to study participants' behaviour, motivations, feelings, values, attitudes and perceptions (Muchinsky, Kriek \& Schreuder, 2005). Interpretive research employs the notion that it is only through social constructions such as language, consciousness, shared meaning and instruments that reality is made available (Myers, 2009). It was therefore an appropriate philosophical approach as the researchers were able to gain insight into, and a deeper understanding of, the contemporary ethical challenges experienced and emotionally perceived by the individual coaching psychologists.

Exploratory research is an approach to qualitative research in which the primary motivation is to discover and explore new phenomena (Myers, 2009) and gain a greater understanding of a concept (McKenzie \& Danforth, 2009). An exploratory approach allowed the researchers to explore the contemporary ethical challenges encountered by coaching psychologists when both dealing with organisations and coaching clients within that organisation. 


\section{Research strategy}

As it was of relevance to this research study and linked to the interpretive philosophical paradigm, a phenomenological research strategy was utilised. Phenomenology attempts to understand the meaning of events (Smith, Flowers \& Larkin, 2009) and social reality (Leedy \& Ormrod, 2010) relating to a certain group of individuals in particular situations. The phenomenological strategy enabled the researchers to gain an understanding of the perspectives of the coaching psychologists with regard to the perceived meanings they attach to the ethical challenges that they have experienced. This strategy therefore enabled the researchers to grasp the essential truths of the lived experiences (cf. Byrne, 2001) of the coaching psychologists, as well as their attitudes towards and opinions about the ethical challenges they encounter.

\section{Research method}

The main objective of this qualitative research study was to explore the contemporary ethical challenges in coaching psychology in South Africa. This was achieved by utilising a phenomenological research methodology, which included two phases of data gathering, namely semi-structured interviews and the Delphi technique, both of which are discussed below.

\section{Data collection methods}

In phase one of the study, semi-structured interviews were employed in order to gain rich and in-depth information (Polkinghorne, 2005; Ryan, Coughlan \& Cronin, 2009) from the participants regarding the ethical challenges that they have encountered when dealing with both their coaching clients and the clients' organisations. This process entailed one-onone interviews that made use of open-ended questions and probes, based on the principle of allowing the interviewee control over the interview process (Ryan et al., 2009). The use of semi-structured interviews enabled the researchers to pursue a series of less-structured questions and explore any spontaneous issues raised by the interviewees. As such, a 'backbone' of main questions guided the interview process and allowed the interviewees to relate their personal experiences of the contemporary ethical challenges as coaching psychologists, whilst still encouraging flexibility in responding.

Typical questions that were addressed in the semi-structured interviews included: (1) the participant's background in psychology and the influence this has on the style of coaching, (2) the ethical challenges experienced when coaching, (3) the ethical challenges that stem from the coach, the coachee, as well as their collaborative relationship, (4) best ethical practice, (5) the ethical challenges that result from boundary issues, (6) the ethical challenges that stem from multiple relationships, (7) the ethical principles that support coaching psychology, (8) the key components involved in making ethical decisions and (9) the impact that the development of an ethical code may have on coaching psychology.

In order to ensure that the data gathered from the semistructured interviews was documented in an accurate and factual manner, and having gained informed consent from the participants, the researchers voice-recorded each interview. In addition, the researchers kept notes in order to capture their responses in detail. Having recorded the data as such, the researchers were able to transcribe the interviews.

The questions asked in the semi-structured interviews, coupled with a comprehensive literature review, guided the researchers in the development of an exploratory framework of ethical challenges. This framework was based on the central ethical challenges identified and experienced by coaching psychologists that could, in turn, inform the development of ethical principles in the field of coaching psychology in South Africa. Thereafter, the framework of ethical challenges was validated, utilising the Delphi technique, which constituted the second phase of the data collection process. Before applying the Delphi technique, a peer review was undertaken to clarify the framework and questions to be utilised in the Delphi technique. Three registered psychologists who met the minimum requirement for participation were used. Once this stage was completed, the next phase was implemented.

In the second phase of the study, the exploratory framework was presented to a panel of knowledgeable experts (Walmsley, Rivett \& Osmotherly, 2009), utilising the Delphi technique. The Delphi technique was considered appropriate as it is typically used to address complexity and uncertainty in an area where knowledge is imperfect or unknown and where some agreement is required (Donohoe \& Needham, 2009). Different versions of the Delphi technique emerged based on variations in the application of consensus, namely the numeric version producing quantitative responses and the policy and historic versions that produce more qualitative responses (Amos \& Pearse 2008). The policy Delphi focuses specifically on the exploration, generation and definition and description of several alternatives, whereas the historic Delphi has a strong retrospective perspective.

For the purpose of this study a policy Delphi was appropriate, as the collective opinions and perspectives (De Villiers, De Villiers \& Kent, 2005) of the experts, on ethical challenges in the field of coaching psychology, were used as the source of information. An important characteristic of the Delphi technique is that not every opinion is accepted at face value, but through an iterative process must stand up to the scrutiny of the experts in the panel (Amos \& Pearse, 2008). Two rounds of the Delphi technique were used, and a number of important steps were taken, which are discussed below.

Firstly, the researchers formulated and expanded on a set of questions in order to gain a set of assumptions, opinions and perspectives with regard to the exploratory framework informed from the data that was gathered from the semi-structured interviews. Typical questions used in the first round of the Delphi technique related to the following: (1) general opinion of the framework, (2) flow 
of the framework, (3) accuracy of the ethical challenges, as outlined in the framework, (4) accuracy of the ethical principles, as outlined in the framework, (5) accuracy of the ethical outcomes, as outlined in the framework, and (6) components added to the framework. The information obtained from the first round was incorporated into the framework and an adapted framework (see Figure 1), supported by a detailed description of each element therein, was presented to the same panel members. Central to the Delphi technique is the iteration process and providing controlled feedback to panel members of the opinion of their anonymous counterparts (Hallowell \& Gambatese, 2010).

In the second round, the panel of experts recorded their opinions, views and experiences with regard to the revised framework of identified ethical challenges, for further clarification and confirmation, as well as further recommendations to refine the framework (Donohoe \& Needham, 2009). At this stage, optimal data saturation and expert opinion stability or collective agreement (Turoff, 1975) was achieved and a third round was considered unnecessary.

Since the panel members were geographically dispersed, the Delphi technique was conducted electronically and the data was captured per question pertaining to the exploratory framework, as provided by each participant. Anonymity was maintained at all times.

\section{Entrée}

The Interest Group of Coaching and Consulting Psychology (IGCCP) was approached as a collaborator in identifying potential participants for the semi-structured interviews and the Delphi technique, based on the selection criteria relevant to the study. The invitation to participate in the research study came directly from the researchers, accompanied by an endorsement from the IGCCP to demonstrate the importance of the study for the IGCCP. Participation in the research study was voluntary. The invitation to participate was circulated by the researchers to ensure anonymity of participants and confidentiality of the information received.

\section{Sampling}

Purposive sampling was applied for both the semi-structured interviews and the Delphi technique. Six participants, three men and three women, all white and all from different classification categories in psychology, were interviewed. These participants were of value to this particular study, as they were all registered psychologists, situated within South Africa, with a minimum of two years' coaching experience. All the participants coached at different levels within organisations, including young professionals, team leaders, line managers, senior managers and executives.

Since the success of the Delphi technique depends primarily on the careful selection of the panel (Donohoe \& Needham,

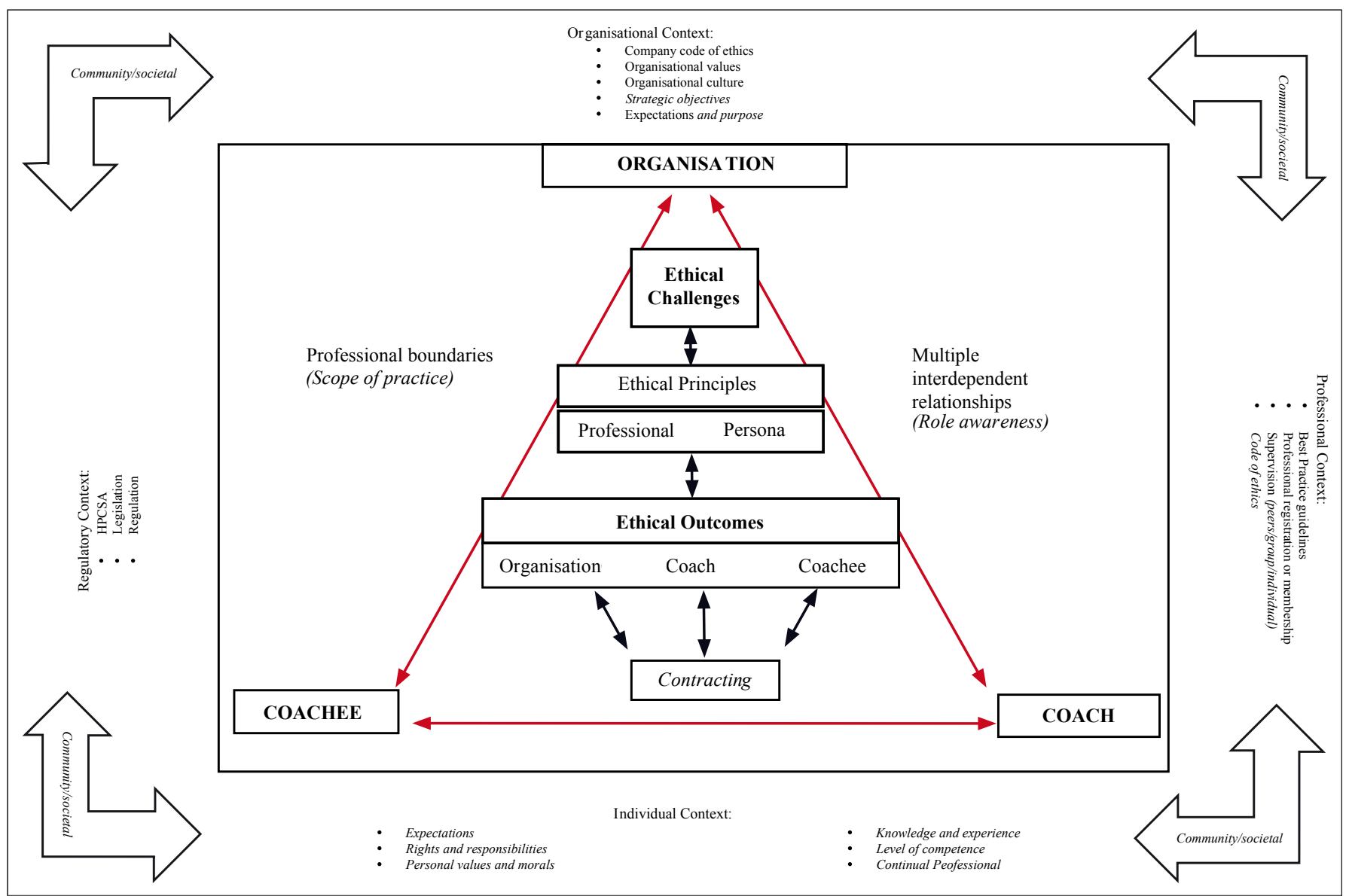

FIGURE 1: Outputs of the first and second round of the Delphi technique: Adapted Exploratory Framework of Ethical Challenges informed by coaching psychologists. 
2009), purposive sampling was best suited, as it sought to purposefully select a panel of expert coaching psychologists with the most information-rich opinions, views and experiences with regard to the ethical challenges that are evident in the field of coaching psychology in South Africa (Amos \& Pearse, 2008; Clayton, 1997). To address the possibility of attrition, a total of 15 coaching psychologist experts were selected for the Delphi technique. In this regard, the original six interviewees, plus nine additional registered psychologists who had coached for a minimum of two years, were invited to participate as the panel of experts for the purpose of the Delphi technique. Feedback was obtained from 10 of the 15 invited panel members, six men and four women, all of whom were geographically dispersed within South Africa.

\section{Data analysis}

Thematic analysis was utilised for both the semi-structured interviews and the Delphi technique, as it enabled the researchers to recognise and describe themes, patterns and regularities that were indicated by the selected group of coaching psychologists regarding their views, opinions and perspectives of the ethical challenges they have encountered. In addition, thematic analysis was useful for this research study, as the analysis process included both inductive and deductive description and interpretation of information obtained (Braun \& Clarke, 2006; Vaismoradi, Turunen \& Bondas, 2013). Verbatim electronic transcripts of the semistructured interviews were utilised by the researchers in analysing and coding the data. The data was analysed per participant, and data gathered per question was clustered into themes based on the components of the exploratory framework obtained through the semi-structured interviews and a literature study (cf. Schurink \& Schurink, 2011). Results obtained from each round of the Delphi technique were noted and categorised under the appropriate theme (De Villiers et al., 2005; Eriksson \& Kovalainen, 2008). Changes to the framework were made after each subsequent round, based on the results of the thematic analysis.

\section{Strategies employed to ensure quality data}

Aligned to the qualitative approach to research, the researchers adhered to a number of criteria (Eriksson \& Kovalainen, 2008) in order to ensure maximum quality, including the following: (1) the research process was carefully documented to enable future researchers to replicate the process; (2) a comprehensive and detailed description of the research process was provided for other researchers to follow and the proposed exploratory framework obtained through the semi-structured interviews was triangulated with a comprehensive literature review; (3) expert opinion stability and subsequent verification of the proposed exploratory framework were ensured; (4) an in-depth description of the integration of the findings and the relevant literature was provided. These elements informed the research design and ensured maximum quality and trustworthiness of the data obtained.

\section{Findings}

This research study focused on the field of coaching psychology, which is characterised by a complexity of ethical challenges that have multiple influences on one another. The findings address and articulate all ethical challenges as perceived by the South African coaching psychologists who participated in the study.

The results from both phases of data gathering, namely the semi-structured interviews and the Delphi technique, are considered and presented. Each phase is discussed below.

\section{Findings from the semi-structured interviews}

The first phase of the research study, namely the semistructured interviews, entailed gathering data from six participants (referred to as P1-P6 in the remainder of the discussion). Once all six interview transcripts had been analysed in detail and the recurring themes and patterns determined, the researchers were able to integrate all the data and draw together and compare the discussions and findings that were established from the data. The findings and the themes and patterns that emerged from the data were delineated into primary themes, some with a number of related secondary themes, as summarised in Table 1.

\section{Background in psychology}

The majority of the participants (P1, P2, P3, P4 and P5) were of the opinion that their training as a psychologist provided them with a greater understanding of human behaviour and ethics. They were of the opinion that having a background in psychology provides coaches with a thorough foundation of all the necessary and relevant theoretical frameworks that they may make use of in the coaching process: 'I am personally biased ... that trained psychologists make the best coaches' (P3).

\section{Triangular relationship}

This refers to the affiliation 'between the coach, the coachee and organisation or the referring party' (P1) and appeared to be the most common theme amongst the participants (P1P6). The participants suggested this as the central ethical challenge encountered when dealing with coaching clients and organisations: 'The biggest challenges that you probably will find are in that three-corner model of the coach, the client organisation and the primary client' (P5).

\section{Non-psychologist coaches}

The term non-psychologist coaches refers to those individuals who do not have any background or training in psychology and who may come from multiple disciplines. The majority of practising coaches are not psychologists or behavioural specialists. It is evident that a wide range of methodological approaches and educational disciplines could potentially inform the practice of coaching, which, as the participants suggested, may result in a wide range of ethical challenges: 
'I think, what has happened with the explosion of people going into coaching ... you get people who think that they can be life coaches because they have had certain experiences. ... So, I think it really has complicated it'. (P3)

\section{Scope of practice}

Scope of practice was defined by the participants as an indication of coaches' self-awareness of what they are trained for and what they can and cannot do. In terms of this study, scope of practice refers specifically to the differentiation between the practices of coaching and counselling. Counselling entails the same process as coaching, but from a clinical perspective. In this regard, a definite line can be drawn between coaching psychology and counselling. The participants were well aware of their scope of practice: 'It has been drilled into you: what are you dealing with, what are you comfortable to do, and what are you trained to do and not to do' (P1).

\section{Feedback}

Feedback entails the extent of disclosure of information that the coach and coachee agree to provide to the organisation as the paying client. Closely linked to the triangular relationship, this ethical challenge, the results indicated, arises as a result of the need to provide the organisation with the necessary feedback regarding the individual, who is both an employee and a coachee: 'Some of the challenges would be around the kind of reporting that the organisation might require' (P6).
Although they had different approaches to providing feedback, all the participants (P1-P6) were in agreement with regard to the clear statement, from the beginning, of what sort of feedback the organisation can expect, provided the coaching client agrees to it:

'The key [to providing feedback], or one of the most important aspects, is to clarify and manage expectations upfront and possibly reinforce that at every coaching session, if not every couple of coaching sessions'. (P4)

\section{Psychometric assessments}

A number of participants (P2, P3 and P6) indicated that they make use of certain psychometric assessments to obtain certain information pertaining to the coachee. This enables the coach to determine where the coachee currently stands and, based on that information, set the goals and objectives for the coaching relationship and measure the outcomes thereof:

'The way that I like to do it is to do very comprehensive assessments at the beginning of a coaching process, and we reassess also at the end, so that we can show the return on investment or the improvement or the change in behaviour, which I think is where we are ahead of the pack'. (P2)

\section{Contracting}

Contracting refers to the process of setting clear boundaries and expectations from the start of the coaching relationship, in agreement with all parties involved, in order to ensure sound

TABLE 1: Summary of primary and secondary themes.

Primary theme
Background in psychology (P1-P4, P6)
Triangular relationship (P1-P6)

Non-psychologist coaches (P2, P3)

Scope of practice (P1-P6)

\section{Secondary themes}

Human behaviour specialist (P1, P3, P4)

Foundation of psychological theories (P1, P4, P5)

Sound knowledge base (P1-P5)

Primary client (coachee) versus paying client (organisation) (P1-P6)

Confidentiality (P1-P6)

Lack of thorough knowledge base (P1-P3, P5, P6)

Coaching versus counselling (P1-P5)

Referring client (P1-P3, P5, P6)

Feedback (P1-P6)

Process feedback versus complete feedback (P1-P5)

Psychometric assessments (P2, P3, P6)

Contracting (P3, P5, P6)

The coach-coachee 'chemistry' process ( $P 2, P 6)$

Freedom of choice (P2, P3, P5, P6)

The appropriate fit (P2, P3, P6)

Diversity (P1-P4, P6)

Supervision (P1-P6)

Ethical decision-making (P1-P6)

Perception of the industry being lucrative (P2, P5, P6

Intention to leave the organisation (P2, P3, P5, P6)

Code of ethics (P1-P6)

Ethical principles (P1-P6)

Assertiveness (P1, P2, P5, P6)
Beneficence (P1, P3, P5)
Respect for autonomy of others (P2, P3, P5, P6)
Transparency (P1-P6)
Trustworthiness and honesty (P1, P2, P3, P5)
Commitment (P5, P6)
Right to feedback (P1-P6)
Disclosure of information (P1-P6)
Professional responsibility (P1)
Confidentiality (P1-P6)
Scope of practice (P1-P6)


ethical practices. More specifically, the contracting process entails an agreement between the coach, the coachee and the organisation with regard to those aspects that are considered appropriate. The contracting phase typically addresses the purpose of the coaching, the duration, the length of coaching sessions, feedback provided and obtained, confidentiality, informed consent to participate and other aspects that need to be agreed-upon prior to commencement of the coaching:

'I think, contracting, which most people would do, is very important. How are we going to work? How are we going to meet? Issues around confidentiality, cancellation of appointments, just so that, upfront, we both understand how this relationship is going to work'. (P3)

\section{The coach-coachee 'chemistry' process}

This entails the matching process between the coach and the coachee, prior to the start of the coaching process, and typically involves matching the coach to the coachee according to factors such as the coach's knowledge and level of experience, as well as the rapport between the two parties. This is a vital step in the coaching process, as an accurate fit between the coach and the coachee in terms of skills, expertise and chemistry enhances the likelihood of success: 'I think it is our ethical responsibility to link, to match people correctly' (P2).

\section{Diversity}

One of the themes that emerged was the importance of the coach in understanding the diverse nature of coaching clients, both from an individual and a cultural perspective. This was a dominant theme, as all the participants (P1-P6) made reference to it:

'Diversity is something we must look at: cultural diversity and the ethical issues from cultural diversity and diversity in general, not just colour and language, but religion and all of that'. (P1)

\section{Supervision}

Supervision entails monitoring the progress of the coach in order to evaluate their performance. By supervising coaches, one is able to monitor whether the coaching relationship is progressing as expected, and whether it is resulting in successful outcomes:

'This is more a monitoring process for me to see how the coach is doing and to monitor the progress that the coach is making, but also to evaluate the performance of the coach'. (P2)

\section{Ethical decision-making}

Coaches are often faced with situations in which sound ethical decisions are required. These decisions are based on a number of personal values or components specific to the coach. The results indicated that the coaches made ethical decisions based on their ethical principles.

\section{Perception of the industry being lucrative}

As suggested by some of the participants (P2, P5 and P6), the coaching field is a lucrative industry, which means that it has produced a great deal of wealth and is considered highly profitable. This, however, can become problematic, in that potential earnings may outweigh best ethical practice, thus leading to an additional ethical challenge. One participant (P2) suggested that, at times, coaches may make incorrect judgements to get the job: 'Sometimes coaches make less good judgment and compromises that you should not make, [for the sake of] putting the bread on the table and getting a job' (P2).

Another participant (P5) asserted that, as a result of the potential earnings of coaching and the unregulated nature of the industry, many individuals, some with very little awareness of best ethical practices, are encouraged to enter the market. This, the participant believed, is one of the greatest challenges in the field of coaching: 'One central thing, one of the biggest problems with coaching, is that it is lucrative' (P5).

\section{Intention to leave the organisation}

An additional ethical challenge that was evident in the data referred to the coachee's intention to leave the organisation. A number of participants (P3, P5 and P6) pointed to this as an ethical challenge for the reason that, when development is involved in the coaching process, it is fair to assume that the coachee may intend to leave the organisation. The coachee (employee) may recognise the need to move on to allow for personal growth and development. One participant (P3) was of the opinion that intention to leave the organisation is a big challenge, but suggested that if this likelihood is made clear when contracting with the organisation, the coach is less likely to be blamed for the loss of an employee. Another participant (P5) stated that an employee's intention to leave does not become problematic, provided that the organisation is aware of the possibility from the onset of the coaching process: 'It is a fair assumption that people who contract with somebody for development purposes know that development is an open-ended thing' (P5).

\section{Code of ethics}

A code of ethics refers to moral guides to self-regulation that endeavour to ensure the appropriate use of skills and techniques (Twain, 1995). It includes those principles specifying the rights and responsibilities of professionals in their relationships with each other and with the people they serve. The ethical principles on which these codes of ethics are based may assist coaching psychologists in their work and are currently used as a guideline to best practice within the coaching arena. Participants P1, P3, P4 and P6 made mention of a number of available codes that they currently use in the field of coaching. These include the HPCSA's best practice guidelines (P1, P3 and P4), the code of conduct provided by the ICF (P4 and P6) and COMENSA's code (P1, P4 and P6).

In addition, participants P2 and P5 were of the opinion that, although a number of codes are available that can be utilised by coaches as guidelines to best ethical practice and provide the scope of practice for psychologists, there are a number of gaps in these codes with regard to the field of coaching: 
'It [HPCSA code of ethics] describes the scope of practice for psychologists, but there are clear gaps and reasons why we need a code of ethics for coaches, because you also need to understand what is your scope of practice depending on as a coach, what your previous training was and what your coaching training was'. (P2)

\section{Ethical principles}

A number of ethical principles were evident in the data obtained from the participants who were interviewed by the researchers. It became increasingly apparent that, when faced with a variety of ethical challenges, there are certain ethical principles that psychologists employ in making an ethical decision. The participants, all of whom were registered psychologists, made use of the ethical principles listed hereunder to guide their conduct in a coaching relationship. These principles are delineated into personal and professional categories. Personal ethical principles are those that reflect the general expectations of people within society, whilst professional ethics are those principles that guide professional conduct. These ethical principles are summarised in Table 2.

As a subsequent step, the information obtained from the six semi-structured interviews, which was supported by the literature review, was utilised to develop an exploratory framework of ethical challenges. This framework was based on the central ethical challenges identified and experienced by the participants and was subjected to the Delphi technique.

\section{Findings from the Delphi technique}

The second phase of the research study, namely the Delphi technique, entailed data gathered on the pooled opinions and perspectives on ethical challenges in the field of coaching psychology from 10 expert coaching psychologists in South Africa. As a result of the distinctive nature of the Delphi technique, the findings obtained are presented according to each round of responses. Two rounds were utilised; the feedback received, the changes proposed and the general comments provided by the participants were all taken into consideration. Based on an integration of the information gained from the six semi-structured interviews, as well as the abovementioned primary and secondary themes, as identified by the researchers, an exploratory framework of ethical challenges was developed. The main focus of

\begin{tabular}{ll} 
TABLE 2: Personal and professional ethical principles as indicated by the results. \\
\hline Principles & Ethical principles results \\
\hline Personal ethics & Assertiveness (P1, P2, P5, P6) \\
& Beneficence (P1, P3, P5) \\
& Respect for autonomy of others (P2, P3, P5, P6) \\
& Transparency (P1-P6) \\
& Trustworthiness and honesty (P1, P2, P3, \& P5) \\
& Commitment (P5 \& P6) \\
& Right to feedback (P1-P6) \\
& Disclosure of information (P1-P6) \\
Professional ethics & Impartiality or objectivity (P1) \\
& Professional responsibility (P1-P6) \\
& Confidentiality (P1-P6) \\
& Scope of practice (P1-P6)
\end{tabular}

the framework is the triangular relationship between the coach, the coachee and the organisation, as the majority of the ethical challenges, ethical principles and ethical outcomes lie therein.

From the results obtained from the semi-structured interviews, it became increasingly evident to the researchers that there are a number of ethical principles that coaching psychologists rely on when making ethical decisions. For this reason, these ethical principles were included in the framework. Furthermore, when faced with an ethical challenge and utilising these ethical principles as a guideline to best practice, the participants made it clear that the result should be an ethical outcome and, hence, this concept was incorporated into the framework. The external influences that surround the triangular relationship were deemed important and therefore included, as these have an indirect influence on the ethical challenges, ethical principles and ethical outcomes.

The framework was presented to the panel of experts in the first round of the Delphi technique, together with an indepth explanation of each related component. It was sent to 15 expert panel members with the intention of gaining their collective opinions and perspectives with regard to the framework. Feedback from 10 expert panel members was obtained. Utilising the suggestions and comments provided by the panel of experts in the first round of the Delphi technique, the framework of ethical challenges, along with an in-depth explanation of each component, was adapted accordingly.

In the second round of the Delphi, the panel of experts recorded their opinions, views and experiences with regard to the revised framework of identified ethical challenges for further clarification and confirmation, as well as further recommendations for refining the framework. Figure 1 presents the integrated outputs of the first and second round of the Delphi technique. At this stage, optimal expert opinion stability or collective agreement (Turoff, 1975) was achieved and it was not deemed necessary to undertake a third round of the Delphi technique (De Villiers et al., 2005; Vernon, 2008). ${ }^{2}$

\section{Discussion}

The research study aimed to explore the contemporary ethical challenges that coaching psychologists in South Africa experience when working in collaboration with coaching clients and organisations. Once these ethical challenges had been established, as informed by the participants, the researchers developed an exploratory framework of ethical challenges, which, in turn, led to ethical principles that can be utilised in resolving the ethical challenges faced by coaching psychologists (see Figure 1).

This research study recognises those areas in which there are no clear ethical guidelines, through the identification of

2.Information that is presented in italics in Figure 1 represents inputs gained through Round 1 of the Delphi technique. 
ethical challenges, ethical principles and ethical outcomes. This, in turn, may serve to raise awareness amongst coaching psychologists regarding the complexity of ethical challenges evident in the field of coaching psychology. Overall, the framework raises awareness and understanding of ethical challenges in order to promote sustainable ethical behaviour.

The field of coaching psychology is characterised by a complexity of ethical challenges that have multiple influences on one another. This is evident in the findings, which indicated a broad, systemic outline of the factors that contribute to these ethical challenges, as well as the nonlinear, multiple interactions between these factors.

The framework of ethical challenges addresses and articulates all ethical challenges, as perceived by the coaching psychologists, and each fundamental factor will be discussed in some detail, below.

\section{Contextual influences}

The contextual influences consist of all those factors that have an indirect impact on the coaching relationship. A number of important external factors were identified by the coaching psychologists as important to the coaching relationship, as these affect the purpose of the coaching relationship, the perspective or approach utilised, as well as the process to be followed in order to ensure a successful outcome. These findings are similar to those of Lane and Corrie (2009), who indicate that it is important to appreciate the broader context of the coaching relationship and that which gives meaning to the purpose of the coaching intervention, as well as the way in which it has come to be defined. From the findings, it is suggested that these contextual influences include the organisational context, the regulatory context, the professional context, the individual context, as well as the community or societal context.

The organisational context is an important influential factor, as the link between the goals of the organisation and the personal goals of the coachee must be considered, so as to ensure a successful coaching relationship. Brennan and Wildflower (2010), Lane and Corrie (2009), as well as StoutRostron (2009), are in agreement with this notion and suggest that the need for coaching and an understanding of the expectations of the key stakeholders are fundamental to the purpose of the encounter and the reason for working with the particular client.

The regulatory context refers to the regulatory bodies and relevant legislation and regulations that pertain to, guide and inform the profession. The findings suggested that, since coaching psychology is emerging as an applied field of psychology, coaching psychologists in South Africa currently make use of the ethical guidelines provided by the HPCSA to ensure good ethical practice. The HPCSA is guided by a regulatory framework, including the Health Professions Act (Act No. 56 of 1974) and the subsequent Health Professions Amendment Act (Act No. 29 of 2007). The acts govern all activities, clearly define the scope of practice of each health profession and set clear processes to be followed (HPCSA, 2004).

The research participants, however, indicated that these ethical guidelines may not necessarily cover all important aspects specific to the field of coaching psychology. This belief is similar to that of Twain (1995), who suggests that the ethical principles on which these codes of ethics are based may well assist the coaching psychologist when working with an individual, team or organisation, but are not infallible and may not cover all important ethical challenges. Peltier (2010), who is in alignment with this idea, suggests that, when psychologists make the transition from counselling to coaching, there exists a variety of unclear ethical challenges, including establishing who the client is, issues around confidentiality, informed consent, boundaries, termination of the coaching relationship, as well as the duty to protect or warn.

Whilst the regulatory context emphasises compliance, the professional context focuses more specifically on professional practice, ethics and standards. The participants in this study were all registered psychologists of a particular registration category, and were enjoying the status of a profession that is based on a unique body of theory or knowledge, with its members possessing specific skills or techniques based on this knowledge. The results therefore suggest growing awareness of the potential benefits of a professional status to the coaching industry. Moreover, the findings, in alignment with Gray (2011), show that the field of coaching is moving towards the professional standards and practice of psychology, implying the importance of the professional context as an influential factor.

This is validated by research conducted by Grant (2006), Grant et al. (2010), Lane et al. (2010), as well as Palmer and Whybrow (2007), who make a strong case for both the suitability and credibility of psychologists as coaches, especially due to their training as scientist-practitioners, their understanding of validated change methodologies, their ability to develop coaching interventions based on theoretically grounded case conceptualisations utilising evidence-based procedures and techniques, the enforceable codes of ethics governing the profession and barriers to entry related to the profession.

The individual context, which, in this study, refers both to the coach and the coaching client (coachee), was characterised differently for the two parties. This infers that there are particular standpoints subscribed to by the coach and the coachee that are important to consider and that have an influence on the coaching relationship. Gregory and Levy (2012) show that the coaching relationship lays the foundation from which effective coaching may ensue and is dependent on the role of the coach and coachee. Knowledge and experience, level of competence and continuous professional development are fundamental to the efficacy of the coach, 
especially when working with heterogeneous clients (Palmer \& Whybrow, 2005). Stern and Stout-Rostron (2013) are in support of this notion and suggest that the competencies, characteristics and practices of the coach have a profound impact on the outcome of the coaching relationship. Moreover, Law (2005) proposes the idea of embedding ethical principles as part of the core competence and continuous development within the profession. Lane and Corrie (2009) suggest that of equal significance are the perspectives that the coachee brings to the relationship, which the findings of the current study identified as the expectations, rights and responsibilities, as well as the personal morals and values of the individual.

Finally, the community or societal context refers to the professionals' endeavour to contribute to the betterment of society in accordance with their professional abilities and standing in the community. In this regard, the findings of the current study can be linked to those of Brennan and Wildflower (2010), who suggest that coaches have a responsibility to engage as professionals and to recognise their responsibility and contributions to their clients, colleagues and to society as a whole. Stern and Stout-Rostron (2013) indicate that, of late, coaching has been moving out into the broader community and thus has a positive impact on society. The ability of coaches to create and maintain an ethical community of coaches is as critical as ethical behaviour within a coaching relationship. Recognising diversity and cultural differences are key characteristics of ethical behaviour, particularly within a multicultural context.

\section{Professional boundaries}

The term professional boundaries was defined as the coaching psychologist's ability to operate from a registered scope of practice and to refer the coachee when they present with themes that are outside of the coach's current knowledge, skills, abilities and level of competence. This notion is much in line with that of Duffy and Passmore (2010), who state the importance of understanding the boundaries and implications involved in a particular situation, as well as the Health Professions Act (Act No. 56 of 1974), which defines the scope of each registration category within the psychology profession.

The findings of the current study further suggest that the concept of professional boundaries also relates to the boundaryless entry that characterises the field of coaching, but with slightly less emphasis than is placed on scope of practice. It can be suggested that by this it is meant that the field of coaching is an unregulated market that is open to a multitude of disciplines (Grant \& Zackon, 2004; Palmer \& Whybrow, 2005), with individuals entering with various backgrounds and training. This is closely linked to the suggestion by Grant et al. (2010) that there are no boundaries to entry, no minimal or requisite educational process or specified training routes and no binding ethical or practice standards within the field of coaching.
As a result of the broad variety of perspectives and approaches in coaching, many ethical challenges may arise, thereby intensifying the depth and extent of ethical challenges experienced and the complexity thereof. The findings of the current study are therefore similar to those of Duffy and Passmore (2010), who emphasise the importance of recognising that coaching is a multidisciplinary industry, characterised by its own ethical challenges and complexities, all of which have a profound impact on the triangular relationship between the coach, the coachee and the organisation.

\section{Multiple interdependent relationships}

The multiple interdependent relationships, referred to by the participants as the triangular relationship, are the relationship between the coach, who provides the service, the coachee, who is considered the primary client, and the organisation, which is, in most cases the paying client. This means that, together, these three parties form dual, multiple and interdependent relationships (Brennan \& Wildflower, 2010; Duffy \& Passmore, 2010), each playing a particular role that has a direct impact on the ethical challenges that are evident in the field of coaching psychology.

Brennan and Wildflower (2010), Duffy and Passmore (2010), Law (2005) and Stout-Rostron (2009) state that the kinds of ethical challenges that coaching psychologists may be faced with as a result of this triangular relationship include: the need, as well as the importance thereof, to determine who the clients are, which stakeholders have priority (the primary client) and whose interests the coach should be serving, ethical obligations as a psychologist, how diverse values and interests may be managed, issues of confidentiality and the amount of feedback provided to the organisation, the potential for client manipulation or dependency and consequences of indirect responsibility.

\section{Contracting}

From the findings, it is evident that contracting refers to the process of setting clear boundaries and expectations from the start of the coaching relationship and in agreement with the coach, the coachee and the organisation, in order to ensure that sound ethical practices are adhered to and that the agreed-upon outcome is achieved. Similarly to the findings of this study, Stern and Stout-Rostron (2013) suggest that the contracting phase includes the formal and informal agreement between coaches, coachees and organisations. Hazen and Steckler (2010) and Spinelli (2008) state that coaching contracts should be open, clear and explicit, and are typically used between the coach, the coachee and the organisation to agree upon an outcome. Similarly, Duffy and Passmore (2010) and Lane and Corrie (2009), whose findings were similar to those of the current study, indicate the importance of the contracting phase and suggest that entering into implicit (implied) and explicit (formal agreement) contracts with clients makes it possible to structure the coaching process that will be undertaken by the coach and coachee. 


\section{Ethical challenges}

During the initial investigation of the ethical challenges faced by coaching psychologists, it became evident that the available codes of ethics may not fundamentally cover all the important ethical challenges, particularly within the South African context. Duffy and Passmore (2010) indicate that professional coaching bodies each have their own code of ethics that may not essentially cover all significant ethical challenges and which may be seen as somewhat overly prescriptive, as only valid in a limited number of situations and as containing certain principles that are contradictory when applied to certain ethical challenges.

The findings of the current study suggest that the ethical challenges, as identified and confirmed by the participants, are informed by contextual influences, the triangular relationship, as well as professional boundaries. The result of these influential factors is complex ethical challenges. The most common ethical challenges that were identified are summarised in Table 3.

\section{Ethical principles}

The findings of the current study point to the ethical principles (see Table 4) most commonly used by psychologists as a guide to best ethical practice. The focus of this research study was on the contemporary ethical challenges faced by coaching psychologists; specific attention was paid to individuals who are registered psychologists, who have explicit ethical and professional standards and codes to which they should legally adhere (in accordance with their respective scope of practice). This implies that, for the very reason that coaching psychology is emerging as an applied field of psychology (cf. Gray, 2011), coaching psychologists typically make use of those ethical guidelines and professional standards as regulated by the HPCSA. Similarly, coaching psychologists in South Africa also make use of those ethical principles as indicated by COMENSA, the ICF and the ISCP. The ethical principles, identified and supported by the participants, are summarised in Table 4.

Inidentifyingboth the contemporaryethicalchallengesfaced by coaching psychologists and the typical ethical principles used as a guide to best ethical practice, the findings showed a number of ethical outcomes present in a typical coaching relationship.

\section{The ethics outcomes}

When faced with ethical challenges, coaching psychologists make use of a number of ethical principles as a guideline to best ethical practice, resulting in an ethical outcome. From the findings, it can be suggested that coaching typically

TABLE 3: Ethical challenges as identified and supported by coaching psychologists in South Africa.

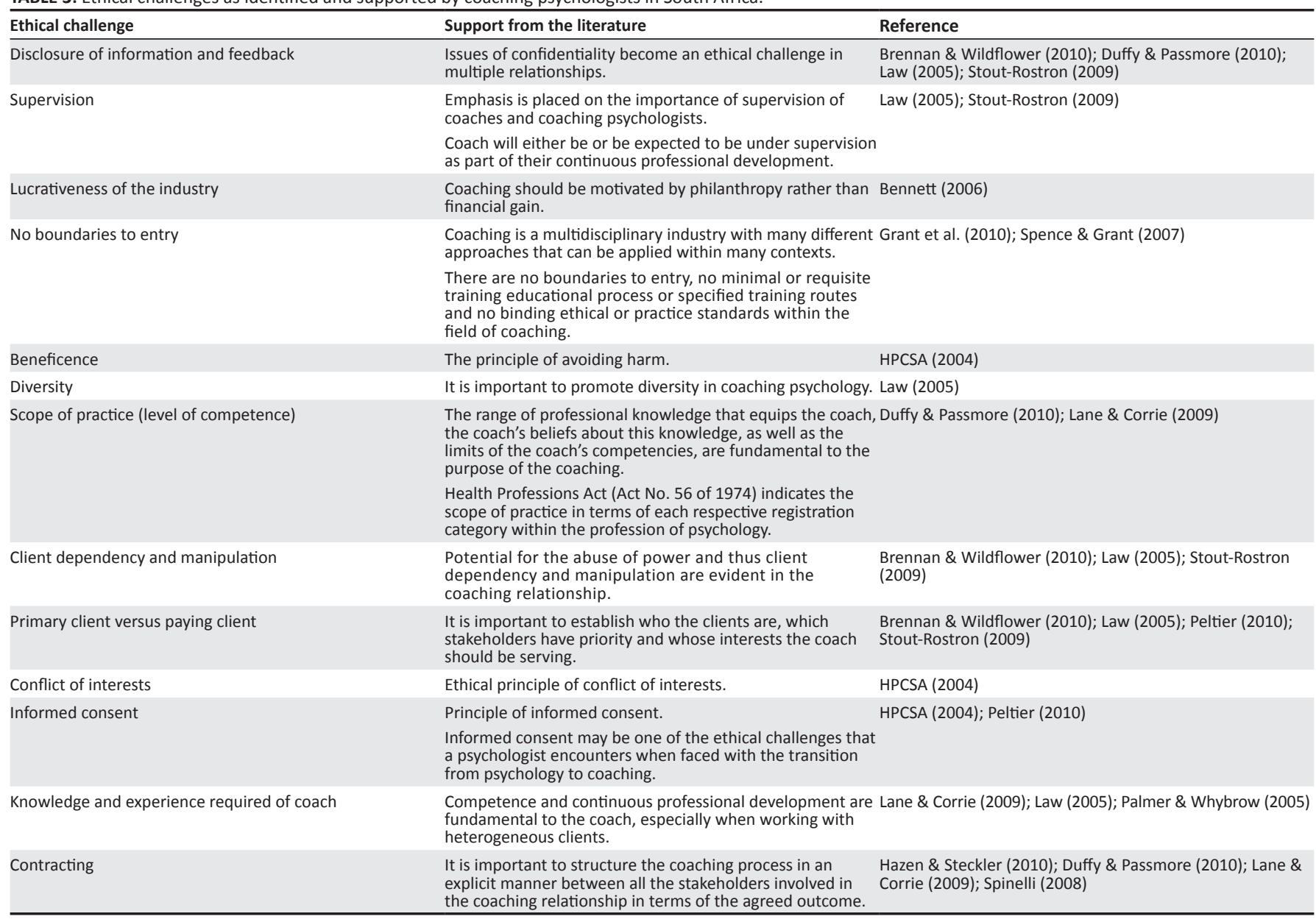


places an emphasis on the collaborative relationship that is formed between coach, coachee and organisation. In order for the coaching process to be effective and yield substantial results, it is important that attention be paid to ethical standards and procedures. As a result of the complexity and systemic nature of the triangular relationship, the ethical outcomes, as depicted in Table 5, are applicable to the coach, the coachee and the organisation.

Based on the rich and in-depth data obtained through the use of semi-structured interviews, an exploratory framework of ethical challenges was established. This, in turn, allowed the validation of the exploratory framework that encompasses the ethical components observed to be integral in the coaching relationship. The framework facilitates the establishment and understanding of the typical ethical challenges encountered by coaching psychologists and thus a greater appreciation and understanding thereof was achieved. Through integrating the findings of this study with relevant literature, it became increasingly evident that this study recognises those areas in which there are no distinct ethical guidelines, through the identification of ethical challenges, ethical principles and ethical outcomes.

\section{Limitations of the study}

Specific to this study, four limitations were identified. Firstly, since this study focused on exploring the contemporary ethical challenges as experienced by coaching psychologists in South Africa, it can be argued that it is not an all-inclusive representation of the ethical challenges within the field of coaching. This is due to the fact that the study only focused on the ethical challenges from the coaches' perspectives, with failure to recognise those experienced by the coachee, managers and organisations involved in the coaching relationship. Secondly, academic literature on coaching psychology is somewhat limited, because the development of the coaching psychology industry nationally and internationally is still in its infancy. Since the available literature on coaching psychology emanated mainly from the prominent thought leaders within the field of coaching psychology in Australia and the United Kingdom, a paucity of information is available on the typical ethical challenges

TABLE 4: Ethical principles as identified and supported by the South African coaching psychologists.

\begin{tabular}{|c|c|c|c|}
\hline Principle & Support from the literature & Principle & Support from the literature \\
\hline Right to feedback & $\begin{array}{l}\text { HPCSA (2004); COMENSA (2006); ICF (2011); } \\
\text { ISCP (2011) }\end{array}$ & Assertiveness: standing firm & $\begin{array}{l}\text { HPCSA (2004); COMENSA (2006); ICF (2011); } \\
\text { ISCP (2011) }\end{array}$ \\
\hline Impartiality or objectivity & HPCSA (2004) & Beneficence & HPCSA (2004) \\
\hline Confidentiality & $\begin{array}{l}\text { Brennan \& Wildflower (2010); COMENSA } \\
\text { (2006); Duffy \& Passmore (2010); HPCSA } \\
\text { (2004); Law (2005); Peltier (2010); Stout- } \\
\text { Rostron (2009) }\end{array}$ & Honesty and integrity & COMENSA (2006); Peltier (2010) \\
\hline Service orientation (duty to society) & Brennan \& Wildflower (2010) & Respect for autonomy of others & $\begin{array}{l}\text { Duffy \& Passmore (2010); HPCSA (2004); } \\
\text { ISCP (2011) }\end{array}$ \\
\hline Informed consent & HPCSA (2004); Peltier (2010) & Trustworthiness & HPCSA (2004) \\
\hline $\begin{array}{l}\text { Professional competence (scope of practice) } \\
\text { and continuous professional development }\end{array}$ & $\begin{array}{l}\text { The Health Professions Act (Act No. } 56 \\
\text { of 1974); Duffy \& Passmore (2010); Lane } \\
\& \text { Corrie (2009); Law (2005); Palmer \& } \\
\text { Whybrow (2005) }\end{array}$ & Commitment to client growth & Grant (2006) \\
\hline Context & Lane \& Corrie (2009) & - & - \\
\hline
\end{tabular}

TABLE 5: Ethics outcomes as identified and supported by the South African coaching psychologists.

\begin{tabular}{|c|c|c|}
\hline Outcome & Support from the literature & Reference \\
\hline Transparency & $\begin{array}{l}\text { Importance of being open and sharing information, } \\
\text { as well as best practice, is emphasised. }\end{array}$ & Peltier (2010) \\
\hline Beneficence & Concept of doing good and avoiding harm. & HPCSA (2004) \\
\hline Referral when necessary & $\begin{array}{l}\text { This ethical outcome will result when coaches recognise } \\
\text { their own level of skill, competence and knowledge and } \\
\text { they practise within their scope. }\end{array}$ & Duffy \& Passmore (2010); Lane \& Corrie (2009) \\
\hline Confidentiality & Client's right to confidentiality and privacy. & HPCSA (2004); ICF (2011) \\
\hline Integrity & $\begin{array}{l}\text { Integrity is a typical ethical 'virtue' that is clearly understood } \\
\text { by both psychologists and coaches. }\end{array}$ & Peltier (2010) \\
\hline Duty to society & $\begin{array}{l}\text { Coaches have a responsibility to their clients and society as } \\
\text { a whole to conduct themselves professionally and ethically. }\end{array}$ & Brennan \& Wildflower (2010); Duffy \& Passmore (2010) \\
\hline \multirow[t]{2}{*}{ Contracting } & Contracting at the start of the coaching process is vital. & \multirow{2}{*}{$\begin{array}{l}\text { Duffy \& Passmore (2010); Hazen \& Steckler (2010); } \\
\text { Spinelli (2008); Stout-Rostron (2009) }\end{array}$} \\
\hline & $\begin{array}{l}\text { Contracting should be clear and explicit between the coach, } \\
\text { coachee and organisation and express the agreed-upon } \\
\text { outcome. }\end{array}$ & \\
\hline Ethical codes as guidelines to best practice & $\begin{array}{l}\text { Ethical principles, on which the codes of ethics utilised by } \\
\text { psychologists are based, may assist coaching psychologists in } \\
\text { their encounters with both coaching clients and organisations. }\end{array}$ & Grant et al. (2010); Gray (2011); Twain (1995) \\
\hline Freedom of choice & Freedom of choice of clients. & HPCSA (2004); Peltier (2010) \\
\hline Credibility & Credibility of psychologists as coaches. & Grant et al. (2010) \\
\hline Accountability & $\begin{array}{l}\text { Coaching psychologist must acknowledge responsibility } \\
\text { and be accountable for all consequences of their coaching, } \\
\text { whether direct or indirect. }\end{array}$ & Brennan \& Wildflower (2010); ICF (2011) \\
\hline Competitive fee structures & $\begin{array}{l}\text { Coaching operates from a business context and is thus } \\
\text { characterised by a proprietary culture based upon the } \\
\text { premise of a competitive, free market. }\end{array}$ & Brennan \& Wildflower (2010); Peltier (2010) \\
\hline
\end{tabular}


experienced by psychologists who coach elsewhere across globe.

Thirdly, owing to the coaching psychology industry in South Africa being in its formative years, it was difficult to find registered psychologists who had sufficient experience and expertise in the field, resulting in a limited number of panel members in the Delphi technique. Lastly, on account of utilising purposive sampling as a means of participant selection, different participants will in all likelihood take part in future follow-up studies and, as a result, other themes may emerge, as they may share diverse perspectives in terms of the ethical challenges they experience.

\section{Recommendations}

Since this research study was exploratory in nature, further research on the topic should be undertaken. Future research could benefit from including both the coaching clients and organisations as participants in the study, in order to broaden the offerings and awareness of the ethical challenges in the field of coaching. Furthermore, future research may also reap substantial benefits from designing a questionnaire based on the framework of ethical challenges. This may, in turn, validate the framework through quantitative research.

The field of coaching psychology may benefit from this research study, as it has opened a conversation regarding the role of ethics in coaching psychology in South Africa and addressed a variety of specific ethical challenges prominent in a multicultural context. Furthermore, the development of the framework of ethical challenges, which identifies both ethical principles and ethical outcomes, can be used as a guideline to best ethical practice, as well as ethical decision-making, particularly regarding the triangular relationship evident within the coaching relationship. Finally, the framework can be used by coaching psychologists when contracting, to inform and promote ethical behaviour and encourage coaching psychologists to act in a professional and ethical manner.

The coaching clients, which refers to all those stakeholders involved in the coaching process, may benefit from this study for a number of reasons. The framework raises an awareness of the ethical expectations for both the coachee and the organisation. Specific to the coachee, the framework may be utilised in identifying those ethical principles and standards of practice that influence the coach's conduct. The organisation, on the other hand, may make use of the framework to align their governance, requirements, policies and code of ethics with those ethical challenges, ethical principles and ethical outcomes typically evident in a coaching relationship.

\section{Conclusion}

This research study recognises those areas in which there are no clear ethical guidelines, through the identification of ethical challenges, ethical principles and ethical outcomes. This, in turn, may serve to raise awareness amongst psychologists who coach regarding the complexity of ethical challenges evident in the field of coaching psychology. Overall, the aim of developing the framework was to raise awareness and understanding of ethical challenges in order to promote sustainable ethical behaviour.

In clearly addressing the need to identify ethical principles, the framework can be utilised as the foundation for a global code of ethics in coaching psychology. Moreover, as a result of the non-linear, systemic nature of the framework and the ethical components therein, it can be utilised across multicultural organisations, as well as amongst heterogeneous clients, particularly within the South African context, as a means of raising awareness and gaining an in-depth understanding of ethical principles in the field of coaching psychology. This awareness and thorough understanding of the ethical challenges, along with the identification of the ethical principles and ethical outcomes, serve to inform and promote ethical behaviour and encourage coaching psychologists to practise the maximum level of professionalism and ethical conduct.

\section{Acknowledgements Competing interests}

The authors declare that they have no financial or personal relationship(s) that may have inappropriately influenced them in writing this article.

\section{Authors' contributions}

C.E.S (University of Johannesburg) was the project leader. She performed all the steps leading from the data gathering to the findings, and was responsible for writing the manuscript. A.O. (University of Johannesburg) acted as the supervisor of this master's degree study. She provided expert knowledge in the field of coaching psychology, made conceptual contributions and was responsible for the project design. She furthermore provided guidance and support throughout the study, making suggestions where necessary. X.G. (University of Johannesburg) acted as the co-supervisor of this study. She provided conceptual contributions in relation to the Delphi technique.

\section{References}

Amos, T., \& Pearse, N. (2008). Pragmatic research design: An illustration of the use of the Delphi technique. The Electronic Journal of Business Reasearch Methods, 6(2), 95-102.

Bennett, J.L. (2006). An agenda for coaching-related research: A challenge for researchers. Coaching Psychology Journal: Practice and Research, 58(4), 240-249.

Braun, V., \& Clarke, V. (2006). Using thematic analysis in psychology. Qualitative Research in Psychology, 3, 77-101. http://dx.doi.org/10.1191/1478088706qp063oa

Brennan, D., \& Wildflower, L. (2010). Ethics in coaching. In E. Cox, T. Bachkirova, \& D. Clutterbuck (Eds.), The complete handbook of coaching (pp. 369-380). London, UK: SAGE Publications Ltd.

Byrne, M.M. (2001). Understanding life experiences through a phenomenological approach to research. AORN Journal, 1, 1-5.

Cavanagh, M., \& Grant, A.M. (2006). The personal is the professional. Sydney, Australia: Coaching Psychology Unit.

Cavanagh, M., \& Lane, D. (2012). Coaching psychology coming of age: The challenges we face in the messy world of complexity. International Coaching Psychology Review, 7(1), 75-90.

Clayton, M.J. (1997). Delphi: A technique to harness expert opinion for critical decision-making tasks in education. Educational Psychology, 17(4), 373-386. http://dx.doi.org/10.1080/0144341970170401

COMENSA. (2006). COMENSA code of ethics and standards of professional competence. Retrieved 2011, from http://www.comensa.co.za 
De Villiers, M.R., De Villiers, P.J.T., \& Kent, A.P. (2005). The Delphi technique in health sciences education research. Medical Teacher, 27(7), 639-643. http://dx.doi. sciences education research. Medict
$\mathrm{org} / 10.1080 / 13611260500069947$

Donohoe, H.M., \& Needham, R.D. (2009). Moving best practice forward: Delphi characteristics, advantages, potential problems, and solutions. International Journal of Tourism Research, 11, 415-437. http://dx.doi.org/10.1002/jtr.709

Duffy, M., \& Passmore, J. (2010). Ethics in coaching: An ethical decision making framework for coaching psychologists. International Coaching Psychology Review, 5(2), 140-151.

Eriksson, P., \& Kovalainen, A. (2008). Qualitative methods in business research. London, UK: SAGE Publications, Ltd. http://dx.doi.org/10.4135/9780857028044

Grant, A.M. (2006). A personal perspective on professional coaching and the development of coaching psychology. International Coaching Psychology Review, development $12-22$.

Grant, A.M. (2011). Developing an agenda for teaching coaching psychology. International Coaching Psychology Review, 6(1), 84-99.

Grant, A.M., \& Zackon, R. (2004). Executive, workplace and life coaching: Findings from a large-scale survey of International Coach Federation members. International Journal of Evidence Based Coaching and Mentoring, 2(2), 1-15.

Grant, A.M., Passmore, J., Cavanagh, M.J., \& Parker, H. (2010). A state of play in coaching today: A comprehensive review of the field. International Review of Industrial and Organizational Psychology, 25(1), 125-167.

Gray, D.E. (2011). Journeys towards the professionalisation of coaching: Dilemmas, dialogues and decisions along the global pathway. Coaching: An International Journal of Theory, Research and Practice, 4(1), 4-19.

Green, L.S., Oades, L.G., \& Grant, A.M. (2006). Cognitive-behavioural, solution-focused life coaching: Enhancing goal striving, well-being, and hope. Journal of Positive Psychology, 1(3), 142-149. http://dx.doi.org/10.1080/17439760600619849

Gregory, J.B., \& Levy, P.E. (2012). Employee feedback orientation: Implications for effective coaching relationships. Coaching: An International Journal of Theory, Research and Practice, 5(2), 86-99.

Hallowell, M.R., \& Gambatese, J.A. (2010). Qualitative research: Application of the Delphi method to CEM research. Journal of Construction Engineering and Management, 136(1), 99-107. http://dx.doi.org/10.1061/(ASCE)CO.19437862.000013

Hazen, B., \& Steckler, N. A. (2010). Career coaching. In E. Cox, T. Bachkirova, \& D. Clutterbuck (Eds.), The complete handbook of coaching (pp. 311-323). London, UK: SAGE Publications Ltd.

HPCSA. (2004). Health Professions Council of South Africa. Retrieved 2011, from http://www.hpcsa.co.za.

ICF. (2011). ICF code of ethics. Retrieved 2011, from http://www.coachfederation.org/ includes/media/docs/Ethics-2009.pdf.

ISCP. (2011). International Society for Coaching Psychology code of ethics. Retrieved 2011, from http://www.isfcp.net/ethics.htm.

Lane, D.A., \& Corrie, S. (2009). Does coaching psychology need the concept of formulation? International Coaching Psychology Review, 4(2), 195-208.

Lane, D.A., Stelter, R., \& Stout-Rostron, S. (2010). The future of coaching as a profession. In E. Cox, T. Bachkirova, \& D. Clutterbuck (Eds.), The complete handbook of coaching (pp. 357-368). London, UK: SAGE Publications Ltd.

Law, H. (2005). The new code of ethics, human rights and its implications in relation to coaching psychology practice. The Coaching Psychologist, 2(2), 13-19.

Leedy, P.D., \& Ormrod, J.E. (2010). Practical research: Planning and design. (9th edn.). Upper Saddle River, NJ: Pearson.

McKenzie, K., \& Danforth, S. (2009). Problem definition, exploratory research, and the research. San Francisco, CA: John Wiley \& Sons, Inc.
Muchinsky, P.M., Kriek, H.J., \& Schreuder, A.M.G. (2005). Personnel psychology. Cape Town, South Africa: Oxford University Press Southern Africa (Pty) Ltd.

Myers, M.D. (2009). Qualitative research in business and management. London, UK: SAGE Publications Ltd.

Odendaal, A., \& Le Roux, A. (2011). Emerging trends and challenges in the professionalization of the coaching industry: A South African coaching psychology perspective. Paper presented at the 1st International Congress of Coaching Psychology, 12 October, Barcelona, Spain.

Palmer, S., \& Whybrow, A. (2005). The coaching psychology movement and its development within the British Psychological Society. International Coaching Review, 1(1), 5-10

Palmer, S., \& Whybrow, A. (2007). Coaching psychology: An introduction. In S. Palmer, \& A. Whybrow (Eds.), Handbook of coaching: A guide for practitioners (pp. 1-20). New York, NY: Routledge Taylor \& Francis Group.

Peltier, B. (2010). The psychology of executive coaching: Theory and application. (2nd edn.). New York, NY: Routledge Taylor \& Francis Group.

Polkinghorne, D.E. (2005). Language and meaning: Data collection in qualitative research. Journal of Counseling Psychology, 52, 137-145. http://dx.doi. org/10.1037/0022-0167.52.2.137

Rossouw, D., \& Van Vuuren, L.J. (2010). Business ethics. (4th edn.). Cape Town, South Africa: Oxford University Press.

Ryan, F., Coughlan, M., \& Cronin, P. (2009). Interviewing in qualitative research: The one-to-one interview. International Journal of Therapy and Rehabilitation, 16(6) 309-314. http://dx.doi.org/10.12968/ijtr.2009.16.6.42433

Schurink, W., \& Schurink, E. (2011). Interviews. Masters 2011: Qualitative Research. Industrial Psychology class notes. Bloemfontein, South Africa: SAGE Publications Ltd.

Sherman, S., \& Frees, A. (2004). The Wild West of executive coaching, Harvard Business Review, 82(1), 82-90.

Smith, J.A., Flowers, P., \& Larkin, M. (2009). Interpretive phenomenological analysis: Theory, method and research. London, UK: SAGE Publications Ltd.

Spence, G.B., \& Grant, A.M. (2007). Professional and peer life coaching and the enhancement of goal striving and well-being: An exploratory study. The Journal of Positive Psychology, 2, 185-194. http://dx.doi.org/10.1080/17439760701228896

Spinelli, E. (2008). Coaching and therapy: Similarities and divergences. International Coaching Psychology Review, 3(3), 241-249.

Stern, L., \& Stout-Rostron, S.S. (2013). What progress has been made in coaching research in relation to 16 ICRF focus areas from 2008 to 2012? Coaching: An International Journal of Theory, Research and Practice, 2(1), 76-85.

Stout-Rostron, S.S. (2009). Business coaching: Wisdom and practice. Randburg, South Africa: Knowres Publishing (Pty) Ltd.

Turoff, M. (1975). The design of a policy Delphi. Technological Forecasting and Social Change, 2(2), 149-171. http://dx.doi.org/10.1016/0099-3964(70)90004-9

Twain, M. (1995). Codes, controls, and ethical decision making. In P. Keith-Spiegel, \& G.P. Koocher (Eds.), Ethics in psychology: Professional standards and cases ( $\mathrm{p}$ 494). New Jersey, USA: Lawrence Erlbaum Associates, Publishers.

Vaismoradi, M., Turunen, H., \& Bondas, D. (2013). Content analysis and thematic analysis: Implications for conducting a qualitative descriptive study. Nursing and Health Sciences, 15, 398-405. http://dx.doi.org/10.1111/nhs.12048

Vernon, W. (2008). The Delphi technique: A review. International Journal of Therapy and Rehabilitation, 16(2), 69-76. http://dx.doi.org/10.12968/ijtr.2009.16.2.38892

Walmsley, A., Rivett, D.A., \& Osmotherly, P.G. (2009). Adhesive capsulitis: Establishing consensus on clinical identifiers for Stage 1 using the Delphi technique. Physical Therapy, 89(9), 906-917. http://dx.doi.org/10.2522/ptj.20080341 